REVISTA DE GESTAOOE SECRETARRADO

MANAGEMENT AND AdMINISTRATIVE

PROFESSIONAL REVIEW

ISSN: 2178-9010
Revista GeSec

São Paulo, SP, Brasil

v. 12 , n. 1, p. $178-204$

jan. /abr. 2021

DOI: http://dx.doi.org/10.7769/gesec.v12i1.1150

\title{
Intenção empreendedora e a influência das teorias do comportamento planejado e dos valores humanos
}

\section{Entrepreneurial intention and the influence in of planned behavior and}

\section{human values theories}

\author{
Déborah Luiza Marcon ${ }^{1}$ \\ Amélia Silveira ${ }^{2}$ \\ Jucelia Appio Frizon ${ }^{3}$
}

\section{Resumo}

Baseando-se na Teoria do Comportamento Planejado (TCP), de Ajzen (1991), e na Teoria dos Valores Humanos (THV), de Schwartz (2001), objetivou-se mensurar a influência do comportamento planejado e dos valores humanos na intenção empreendedora (IE) de estudantes universitários. O método foi quantitativo e o delineamento descritivo. A amostra abrangeu os discentes do $3^{\circ}$ e $4^{\circ}$ anos de 11 cursos de graduação em Administração, no Sudoeste do Paraná, Brasil. A coleta de dados utilizou: Questionário de Intenção Empreendedora (QIE), de Liñán e Chen (2009); Questionário de Perfis de Valores (PVQ), de Schwartz (2001); três itens da Escala de Intenção Empreendedora, de Thompson (2009); e Questionário Sociodemográfico. Por meio da análise de Regressão Linear Múltipla os resultados da TCP evidenciaram que o constructo Atitudes Pessoais foi o mais influente na IE, em relação aos demais. Percepção de Controle do Comportamento posicionou-se em segundo lugar. Para os constructos da THV, os valores de autopromoção se mostraram significativos, influenciando positivamente na IE dos alunos. O modelo baseado na TCP explicou 51,1\% da variância na IE e modelo da THV explicou 51,8\% da variância, constituindo-se em valores médios. A adoção conjunta dos dois modelos permitiu

\footnotetext{
1 Mestre em Gestão e Desenvolvimento Regional, Docente na Especialização em Gestão Empresarial da Universidade Estadual do Oeste do Paraná (Unioeste).

${ }^{2}$ Pós-doutora em Ciencias de La Información e em Administração, Docente da Universidade Federal de Santa Catarina (UFSC).

3 Doutora em Administração, Docente no Programa de Pós-graduação em Desenvolvimento Regional e Agronegócio da Universidade Estadual do Oeste do Paraná (Unioeste).
} 
complementação e ampliação da perspectiva teórica de mensuração da IE. Permitiu evidenciar o interesse dos alunos pela carreira empreendedora, por meio de Atitudes Pessoais, Percepção de Controle de Comportamento e Valores Humanos. Essa perspectiva é nova, inédita e original. Há necessidade das IES pesquisadas se voltarem para a adoção efetiva da educação empreendedora, em função do interesse manifestado pelos alunos.

Palavras-chave: Intenção Empreendedora. Teoria do Comportamento Planejado (TCP). Teoria dos Valores Humanos (THV).

\section{Abstract}

Based on Ajzen's (1991) Theory of Planned Behavior (TCP) and Schwartz's (2001) Theory of Human Values (THV), the objective was to measure the influence of planned behavior and human values on entrepreneurial intention (IE) of university students. The method was quantitative and the design was descriptive. The sample included students from the 3 rd and 4th years of 11 undergraduate courses in Administration, in the Southwest of Paraná, Brazil. Data collection used: Entrepreneurial Intention Questionnaire (QIE), by Liñán and Chen (2009); Values Profiles Questionnaire (PVQ), by Schwartz (2001); three items on the Entrepreneurial Intention Scale, by Thompson (2009); and Sociodemographic Questionnaire. Through the Multiple Linear Regression analysis, the TCP results showed that the Personal Attitudes construct was the most influential in IE, in relation to the others. The Perception of Behavior Control was placed in second place. For the constructs of THV, the self-promotion values were significant, positively influencing the students' IE. The TCP-based model explained $51.1 \%$ of the variance in IE and the THV model explained $51.8 \%$ of the variance, constituting average values. The joint adoption of the two models allowed complementing and expanding the theoretical perspective of measuring EI. It allowed students to show their interest in the entrepreneurial career, through Personal Attitudes, Perception of Behavior Control and Human Values. This perspective is new, unprecedented and original. There is a need for the researched HEI to turn to the effective adoption of entrepreneurial education, due to the interest shown by the students.

Keywords: Entrepreneurial Intention. Theory of Planned Behavior (TPB). Theory of Human Values (THV). 


\section{Introdução}

O empreendedorismo é considerado, na atualidade, um fenômeno importante para o desenvolvimento da economia e um dos motores do crescimento mundial (Schumpeter, 1982; Santos, Sá Barreto, \& Guzman, 2017; Silva, Oliveira, Castro, Silva, \& Veiga, 2020). Nos países menos desenvolvidos, o empreendedorismo não apenas representa forma de estimular o desenvolvimento econômico, mas maneira de enfrentar os desafios sociais e econômicos de uma região (Santos et al., 2017; Renzi, Henz, \& Rippel, 2019; Galvão, 2019). Isto "exige transformação nas bases sociais e econômicas, mudanças estruturais e, sobretudo, uma estratégia construída de forma conjunta entre os diversos atores da região". (Corrêa, Silveira, \& Souza, 2019). Ampliar o conhecimento sobre o comportamento empreendedor e a gama de fatores associados à intenção empreendedora em diferentes contextos culturais é recomendado por Ozaralli, \& Rivenburgh, 2016; Sousa, Fontenele, Silva, \& Souza, 2019; Fernandes, D’Ávila, Cruz, \& Pereira, 2020.

Segundo Silveira, Ferreira, Silvente e Cunha (2017), o tema de intenção empreendedora apresenta constante crescimento e evolução quanto ao número de abordagens sobre o tema. Estudar as características psicossociais que perpassam o empreendedorismo, sobretudo a figura do empreendedor, é uma linha de pesquisa de grande interesse, dada a situação econômica atual e as necessidades do meio organizacional (Moriano, Palací, \& Morales, 2006; Silva et al., 2020).

Dentre as pesquisas realizadas nesse campo, muitas destacam o importante papel que a intenção possui na decisão de começar um novo negócio (Couto, Mariano, \& Mayer, 2010; Moriano, Gorgievski, Laguna, \& Stephan, 2012; Fayolle \& Liñán, 2014; Olmos \& Castilho, 2015; Ozaralli \& Rivenburgh, 2016; Nguyen, 2017; Joseph, 2017; Jie \& Harms, 2017; Silveira, Ferreira et al., 2017; Martins, Santos, \& Silveira, 2019).

A Intenção Empreendedora (IE) situa-se na fase de pré-lançamento e é fator estudado na criação de empresas (Liñán, Nabi, \& Krueger, 2013; Paiva, Souza, Lima, \& Silva, 2020). A intenção é um antecedente direto do comportamento real; e quanto mais forte for a intenção de comportamento, maior será o sucesso da previsão do comportamento (Ajzen, 1991).

Krueger, Reilly e Carsrud (2000) afirmam que as intenções são os melhores preditores da maioria dos comportamentos planejados, incluindo o comportamento empresarial. A intencionalidade da ação (ação de empreender) é fundamentada na psicologia cognitiva, que tenta prever e explicar o comportamento humano (Silveira, Bizarrias, \& Carmo, 2017; Garcez, 2019). 
Nesse sentido, identificar indivíduos com intenções empreendedoras tem se constituído em preocupação e interesse no campo do empreendedorismo. No entanto, também se deve considerar, no bojo dessa identificação da intenção de empreender, o papel dos valores humanos e culturais como possíveis antecedentes de uma Atitude Empreendedora (AE), no marco teórico das intenções (Moriano et al., 2012; Fayolle \& Liñán, 2014; Sousa, E. S., 2020). Algumas pesquisas apontam que a orientação empreendedora de uma população também é influenciada pelos valores e traços culturais dessa nação (Ozaralli \& Rivenburgh, 2016; Araújo \& Bayon, 2017; Jie \& Harms, 2017), e por crenças religiosas (Paiva et al., 2020), que também são consideradas antecedentes da intenção empreendedora. Esses valores humanos e culturais são abordados no Questionário de Perfis de Valores (PVQ), de Schwartz (2001).

Baseando-se nos princípios de duas teorias, a Teoria do Comportamento Planejado (TCP), de Ajzen (1991), e a Teoria dos Valores Humanos (THV), de Schwartz (2001), verifica-se que ambas possibilitam a identificação de atitudes, normas, comportamentos, valores humanos e culturais, e percepções da atividade empreendedora. E que podem ser adotadas em um mesmo estudo sobre IE. Entretanto, até o momento, pouco se conhece sobre a mensuração que nutrem as iniciais empreendedoras quando estas duas teorias são consideradas em conjunto. Assim, apresenta-se a questão norteadora que conduz esse estudo: qual a influência do Comportamento Planejado e dos Valores Humanos nas intenções dos indivíduos para iniciar um novo negócio?

O objetivo de pesquisa consiste mensurar a influência do comportamento planejado e dos valores humanos na intenção empreendedora (IE) de estudantes universitários. Ou seja, mais especificamente: mensurar a Atitude Pessoal, as Normas Subjetivas, o Controle do Comportamento Percebido e os Valores Humanos na Intenção Empreendedora de estudantes universitários da região Sudoeste do Paraná, Brasil.

Estruturado com essa introdução, o artigo se apoia em um referencial teórico básico sobre a TCP (Ajzen,1991) e a TVH (Schwartz, 2001). O método de pesquisa, de caráter descritivo, e com apoio em dados quantitativos e em procedimentos estatísticos, possibilita medir a intenção empreendedora de estudantes universitários e estabelecer resultados sobre padrões e teorias, com associação de variáveis. E, ainda, descrever características de uma população localizada no Sudoeste do Estado do Paraná, Brasil. composta por estudantes universitários, sobre intenção empreendedora. As considerações finais e as referências sobre o material bibliográfico citado complementam o texto. 


\section{Referencial Teórico}

A pesquisa sobre empreendedorismo, por sua própria natureza, é um campo multi e interdisciplinar de investigação e, além disso, é explicitamente aberto e exige novas perspectivas e mais pesquisas e práticas que contribuam para a sua distinção e o seu desenvolvimento (Vanevenhoven, 2013; Franco \& Gouvêa, 2017; Bittencourt, 2019; Sousa et al., 2020).

A intenção empreendedora é uma representação cognitiva da prontidão para realizar um determinado comportamento e um antecedente imediato de comportamento (Vasconcelos, Silveira, Pedron, \& Andrade, 2020). Estudos pioneiros sobre a IE remontam ao final da década de 1980 e, desde então, o assunto atrai o interesse de vários estudiosos, inclusive aqueles da psicologia social e da psicologia cognitiva, visando compreender o papel das variáveis individuais e contextuais (Liñán \& Fayolle, 2015). Conforme observado por Krueger et al. (2000), os modelos de IE funcionam como modelos sólidos e generalizáveis e constituem um marco teórico robusto para analisar e predizer a IE a partir de uma perspectiva integradora e ecossistêmica da pessoa e do seu contexto.

\subsection{Teoria do Comportamento Planejado}

Ajzen (2011) especifica que a ação humana é influenciada por três diferentes fatores: uma avaliação positiva ou negativa de um comportamento (atitudes), a pressão social para realizar ou não o comportamento (normas subjetivas), e a percepção sobre a capacidade de se executar o comportamento (autoeficácia ou percepção do controle sobre o comportamento). Nesse sentido, é preciso verificar que, mesmo quando o indivíduo está de acordo com a importância de adotar certo comportamento e avalia as implicações da eventual ação como positivas, a possibilidade de ele executar uma ação preventiva é escassa caso a percepção de controle seja muito baixa (Ajzen \& Fishbein, 2000). O comportamento direcionado a um objetivo resulta da constatação da relação causal entre a intenção e a ação (Elfving, Brännback, \& Carsrud, 2009; Liñán \& Fayolle, 2015).

A observação de oportunidades de negócio e o desenvolvimento de atitudes e atividades empreendedoras são fortemente influenciados pelas aspirações cognitivas do indivíduo, ou seja, suas intenções empreendedoras. Ao se avaliar a IE, em um grupo, é possível estabelecer conclusões sobre como esse grupo se comporta diante da ideia de começar um negócio próprio (Liñán \& Chen, 2009). 
Na TCP (Ajzen, 1991) esses três constructos ou fatores estão presentes. Com relação ao fator Atitude Pessoal (AP), Ajzen (2005) afirma que as pessoas desenvolvem atitudes com base nas crenças que possuem e sobre as consequências da realização do comportamento. Tais consequências incluem recompensas intrínsecas e extrínsecas, como recompensas financeiras, independência ou autonomia, recompensas pessoais e segurança familiar, todas as quais influenciam favoravelmente a intenção de iniciar um negócio (Vasconcelos et al., 2020; Monteiro, Silva, Sousa, \& Melo, 2020). A atitude a respeito do comportamento empreendedor refere-se ao grau em que a pessoa realiza uma avaliação positiva ou negativa do comportamento. Assim, de acordo com E. S. Sousa (2020), uma atitude favorável estará associada a uma maior intenção de agir.

A percepção do controle sobre o comportamento (PCC), segundo Ajzen (2002), no contexto da atividade empreendedora, também pode ser chamada de autoeficácia empresarial. Krueger et al. (2000) argumentaram que a autoeficácia empresarial influencia muito o comportamento. A propensão de alguém a agir em uma oportunidade refere-se à sua disposição inata de agir sobre as decisões e depende das próprias percepções de controle.

As normas subjetivas (NS) correspondem à pressão social exercida para realizar ou não um comportamento e reflete o efeito dos valores sociais, sendo determinada pela percepção do indivíduo sobre as crenças que as pessoas importantes para ele possuem sobre o comportamento que ele deve realizar e também pela motivação do indivíduo para satisfazer as expectativas que os outros têm sobre ele (Garcez, 2019; Marcon, Silveira, \& Frizon, 2020). A NS é a componente mais social do modelo, visto que incorpora a influência de pessoas significativas para o sujeito na decisão de desenvolver a sua carreira profissional por meio do empreendedorismo (Ajzen, 1987).

Ajzen (2011) afirma que, em geral, quanto mais favoráveis forem as atitudes e as normas subjetivas, mais provável é que se estabeleça uma intenção de comportamento. No entanto, a importância relativa de cada um dos componentes varia de comportamento para comportamento, assim como de população para população. É importante notar que a PCC está relacionada ao comportamento de duas maneiras distintas: indiretamente, pelo impacto nas intenções, e diretamente, influenciando de forma mais direta o comportamento.

Com o intuito de mensurar a intenção empreendedora, Liñán e Chen (2009) propuseram um Questionário de Intenção Empreendedora (QIE), baseando-se na TCP de Ajzen (1991), utilizando os componentes de AP, PCC e NS. O QIE foi desenvolvido para superar limitações de outros instrumentos já existentes para medir a IE (Thompson, 2009), que eram compostos de itens únicos ou não abarcavam todos os aspectos da IE. Mais tarde, 
Liñán, Urbano e Guerrero (2011), subsidiados por novas pesquisas, atualizaram o QIE. O estudo de Rueda, Moriano e Liñán (2015) descrevem as pesquisas realizadas adotando o QIE, como instrumento de medida, principalmente em universidades, e com alunos de cursos de graduação, em diversos países. Estudos recentes sustentam e credenciam esse modelo teórico da TCP, de Ajzen (1991), compreendendo não apenas os fatores psicológicos, mas também os sociais (Jie \& Harms, 2017; Nguyen, 2017; Silveira et al., 2017; Paiva et al., 2020; Vasconcelos et al., 2020, Marcon et al., 2020).

No Brasil, a pesquisa de Couto, Mariano e Mayer (2010) teve como objetivo apresentar os resultados da aplicação de um instrumento de medição da IE. O QIE foi traduzido para o português e aplicado a 254 estudantes do Curso de Graduação em Administração de Empresas da Universidade Federal Fluminense (UFF), entre setembro e outubro de 2009. O teste de validação do QIE mostrou que este não foi capaz de refletir o modelo proposto no contexto brasileiro, o que abre a discussão sobre a aplicação de modelos internacionais a culturas diversas. A ferramenta, por outro lado, mostrou-se útil para identificar as impressões dos estudantes a respeito do comportamento empreendedor e como os fatores externos podem influenciá-lo. Os resultados indicaram que a carreira como empreendedor é percebida como favorável pelos alunos de Administração dos diferentes períodos, sendo vista como mais atraente que o trabalho formal. No entanto, seguir a carreira de empreendedor não é necessariamente uma alternativa positiva na opinião daqueles que cercam os respondentes da pesquisa (família e sociedade), a ponto de ser incentivada.

Ozaralli e Rivenburgh (2016) investigaram os antecedentes do comportamento empreendedor com especial atenção à experiência e educação, ao contexto econômico e político e a fatores de personalidade. O estudo comparou os estudantes dos EUA e da Turquia, com base em pesquisas de 589 alunos júniores e sêniores, em uma universidade estadunidense e em uma turca. $\mathrm{O}$ instrumento de pesquisa foi um questionário elaborado com base em uma análise dos trabalhos desenvolvidos por autores como Krueger et al. (2000), Ajzen (2002) e Liñán e Chen (2009). Os resultados indicaram que, apesar de ter uma atitude positiva com relação ao empreendedorismo, tanto os estudantes estadunidenses quanto os turcos mostram um baixo nível de intenção empresarial. Os achados também indicam que existe uma relação estatisticamente significativa entre os atributos de personalidade ligados a otimismo, inovação, propensão ao risco e intenção empresarial.

Schaefer, Nishi, Grohmann, Löbler e Minello (2017) investigaram a existência de relações positivas entre valores pessoais, AE e IE em estudantes universitários. Utilizando-se do modelo proposto por Watchravesringkan et al. (2013) aplicado em 204 estudantes de 
graduação em Administração de duas instituições de ensino brasileiras no Rio Grande do Sul (uma pública e outra privada), e por meio da modelagem de equações estruturais, os resultados evidenciaram que os valores pessoais influenciaram positivamente a $A E(R=0,152)$ e que a $\mathrm{AE}$ impactou fortemente na $\mathrm{IE}(\mathrm{R}=0,773)$ dos estudantes investigados.

Santos, Teston, Zawadski, Lizote e Machado (2020) desenvolveram um trabalho com foco na capacidade absortiva individual (CAI) e na IE de sucessores de propriedades rurais. Participaram da pesquisa de abordagem qualitativa 84 sucessores. Foram utilizados questionários de autopreenchimento para avaliar tais constructos. Os achados da pesquisa demonstraram que existe uma associação entre os construtos IE e CAI; isso significa que quando maior a intenção de empreender, maior a disposição para adquirir mais conhecimentos com o objetivo de aplicá-los na gestão da propriedade.

\subsection{Teoria de Valores Humanos}

Ao se analisarem locais com culturas distintas, percebe-se que cada uma influenciará a cultura empreendedora local a possuir determinados traços, que nem sempre convergirão em empreendimentos (Saffu, 2003).

Nesse contexto, podem-se analisar as características culturais de uma determinada região por meio de dimensões culturais, que tentam explicar diversos traços e comportamentos da população que lá habita. Dos modelos de dimensões culturais existentes, quatro dos mais difundidos e citados até os dias de hoje são: de Hofstede, de Trompenaars e Hampden-Turner, de Hall e de Schwartz (Pecly \& Ribeiro, 2015).

Schwartz (2001) entende valores como "critérios ou metas que transcendem situações específicas, que são ordenados por sua importância e que servem como princípios que guiam a vida do indivíduo" (p. 55). O autor criou uma tipologia que destaca valores como metas desejáveis e transituacionais, as quais possuem influência sobre as seleções de atitudes e, de acordo com M. M. M. Sousa (2020), podem “. . . variar pela sua importância e nortear a vida do indivíduo ou entidade social como princípios” (p. 41).

Em 1992, Schwartz identificou e descreveu uma lista com 10 valores pessoais principais derivados da existência humana: autodeterminação, estimulação, hedonismo, realização, poder, benevolência, conformidade, tradição, segurança e universalismo (Martins, Sales, \& Reis, 2020).

De forma abrangente, Schwartz (2001) defende na Teoria de Valores Humanos que há 10 tipos motivacionais quase universais que refletem as três necessidades básicas, e que estão 
agrupados em duas dimensões bipolares. Essas podem ser entendidas da seguinte maneira: a primeira dimensão contrasta abertura à mudança e conservação, ela captura o conflito entre a ênfase no pensamento e nas ações independentes do indivíduo que favorecem a mudança (autodeterminação e estimulação) e a autorrestrição submissa, com a preservação de práticas tradicionais e a proteção da estabilidade (segurança, conformidade e tradição); a segunda dimensão contrasta autopromoção com autotranscedência, ela captura o conflito entre a ênfase na aceitação dos outros como iguais, incluindo a preocupação com seu bem-estar (universalismo e benevolência) e a busca pelo próprio sucesso relativo e domínio sobre os outros (autorrealização e poder) (Schwartz, 2006, 2012; Schwartz et al., 2017).

$\mathrm{O}$ hedonismo tem elementos tanto da abertura à mudança quanto de autopromoção. $\mathrm{O}$ que distingue um valor do outro é o tipo de objetivo ou motivação que o valor expressa (Schwartz, 2005). Por meio de pesquisas, os valores pessoais são considerados indicadores das motivações das pessoas, em que as prioridades axiológicas dos membros da organização podem determinar a quantidade de esforço individualmente despendido para realizar um determinado comportamento, bem como a persistência em sua execução (Arce, 2019). Com ênfase específica em empreendedorismo, quatro pesquisas podem ser destacadas: Araújo e Bayon (2017), Fragoso, Rocha-Junior e Xavier (2019), Kasuma, Sapenee, Naimullah, Rahman e Adenan (2019) e Sousa (2020).

A pesquisa realizada por Araújo e Bayon (2017) objetivou determinar o impacto dos fatores socioculturais, como os modelos exemplares de empreendedorismo, e o medo do fracasso na atividade empreendedora dos jovens rurais na Espanha. Os principais achados do estudo foram que na Espanha a probabilidade de ser empreendedoramente ativo não difere entre indivíduos jovens e mais velhos, ou entre os de regiões rural e urbana. Além disso, diferentemente da maioria dos estudos, os modelos exemplares de empreendedorismo não têm qualquer efeito no empreendedorismo dos jovens indivíduos nas regiões rurais da Espanha, enquanto o impacto negativo do medo de fracassar no empreendedorismo desses jovens é muito maior do que para o restante da população.

Fragoso et al. (2019), em pesquisa com estudantes do Brasil e de Portugal, concluíram que traços de personalidade, autoeficácia e atitude empreendedora são fortes preditores de intenção empreendedora, que os efeitos do reconhecimento social e do país de origem não são significativos e que a IE também é fortemente influenciada pelo treinamento e pela educação empreendedora. Ainda, encontraram que a IE dos homens é mais alta do que a das mulheres e que familiares empreendedores geralmente têm influência nos estudantes. 
Kasuma et al. (2019), na Malásia, desenvolveram um estudo para examinar se as capacidades pessoais e os fatores sociais podem influenciar a intenção empreendedora de estudantes de ciência e tecnologia de duas universidades. A pesquisa mostrou que existe uma relação fraca e positiva entre as capacidades pessoais e a IE e que esta é bastante influenciada pelos fatores sociais dos estudantes, visto que as dimensões possuem uma relação forte e positiva. Assim, os autores concluem que o contato com o empreendedorismo e o estudo deste colaboram para a intenção empreendedora dos indivíduos.

Em sua recente pesquisa, Sousa (2020) procurou analisar a influência da orientação religiosa nos valores de autopromoção e de abertura à mudança e nos antecedentes da intenção empreendedora de estudantes universitários de duas universidades, uma brasileira e uma portuguesa. Um dos seus diversos achados mostrou que quanto maior é a orientação religiosa desses estudantes, maior é a sua intenção empreendedora, visto que ela pode ser vista como um princípio que possui influência cultural e institucional sobre a atividade empreendedora. Assim, a autora concluiu que a IE dos estudantes da amostra é diretamente influenciada pela atitude favorável ao empreendedorismo.

\section{Método}

A presente pesquisa tem método quantitativo e abordagem descritiva. O método quantitativo baseia-se na medição numérica e análise estatística para estabelecer padrões e comprovar teorias (Marcon et al., 2020). A pesquisa descritiva está associada à descoberta de associações entre as diferentes variáveis e se caracteriza por descrever as características de uma população ou fenômeno (Monteiro et al., 2020).

Esta pesquisa foi realizada na região Sudoeste do Estado do Paraná, no Brasil.

Definiu-se como população de estudo os estudantes universitários matriculados no $3^{\circ}$ e $4^{\circ}$ anos dos cursos de graduação em Administração, na modalidade presencial, das 11 IES estabelecidas nessa região. A seleção da amostra seguiu orientações de estudos anteriores que utilizaram estudantes de gestão de empresas na investigação empírica sobre a IE. A escolha da amostra foi por conveniência e não probabilística. A participação foi voluntária, com anonimato assegurado, tendo-se obtido o consentimento voluntário de participação dos respondentes.

A coleta de dados foi realizada via computador ou celular, na modalidade em linha. Algumas instituições de ensino disponibilizaram acesso ao laboratório de informática, e todas as instituições disponibilizaram o acesso à internet. A amostra foi significativa, de 403 
estudantes universitários, validando-se 371 respondentes com questionários respondidos corretamente, nas IES pesquisadas. A coleta de dados considerou: (1) Questionário de Intenção Empreendedora (QIE), de Liñán e Chen (2009); (2) Questionário de Perfis de Valores (QPV), de Schwartz (2001); (3) três itens da Escala de Intenção Empreendedora, de Thompson (2009). As questões foram fechadas e escalares, ancoradas em uma escala do tipo Likert, de cinco pontos, que variam de discordo totalmente (1) até concordo totalmente (5). A coleta foi complementada por um Questionário Sociodemográfico.

Apesar do QIE já ter sido traduzido para o português e adotado, testado e validado na realidade brasileira, em estudos recentes (Souza \& Silveira, 2018; Souza, Silveira, \& Nascimento, 2018), optou-se por realizar o teste do Coeficiente Alfa de Cronbach $(\alpha)$ para garantir a confiabilidade de todos os instrumentos. Os resultados demonstram que a confiabilidade (Alfa de Cronbach) foi satisfatória em todos os constructos, pelo que se considera que a consistência interna é adequada. Isso decorre do fato de essa superar o valor recomendado de 0,70 , abaixo do qual a consistência interna da escala utilizada é considerada baixa. O valor máximo esperado é 0,90 , visto que, usualmente, são preferidos valores de Alfa entre 0,80 e 0,90 (Streiner, 2003).

O método de análise de dados adotado considerou a análise de Regressão Linear Múltipla, considerada adequada para o estudo das inter-relações lineares entre variáveis, consistindo em valores de uma variável dependente (variável resposta) e uma ou mais variáveis independentes (variáveis explicativas) (Melo, Silva, \& Almeida, 2019).

As principais métricas utilizadas incluem testes de multicolinearidade, homoscedasticidade e ausência de autocorrelação serial de resíduos para as regressões efetuadas, em que foram atendidos os pressupostos da regressão linear.

\section{Resultados de pesquisa}

Os resultados de pesquisa encontram-se na sequência, compreendendo duas partes: influência do comportamento planejado na intenção empreendedora e influência dos valores humanos na intenção empreendedora.

\subsection{Influência do Comportamento Planejado na Intenção Empreendedora}

O Modelo 1 identifica a influência das atitudes, das NS e da PCC na IE, fortalecendo as teorias que abordam os fatores individuais e ajudam a explicar a intenção de empreender 
(Krueger et al., 2000; Olmos \& Castilho, 2015; Ozaralli \& Rivenburgh, 2016; Oliveira, Vieira, Laguía, Moriano, \& Soares, 2016; Joseph, 2017), conforme Tabela 1.

Os resultados da regressão demonstram que as variáveis preditoras desse modelo respondem por 51,5\% da variância da IE, o que corrobora os achados de Almeida (2013), que aplicou o modelo com estudantes universitários das cinco regiões brasileiras e de Cabo Verde. Além disso, indicou um ajuste satisfatório do modelo na região pesquisada. Os resultados de Almeida (2013) demonstraram um percentual de explicação variando de 60,6 a 76\% entre as regiões brasileiras estudadas em sua pesquisa. Mais precisamente na região Sul do Brasil, o autor evidenciou uma variância de 69,2\% das variáveis preditoras em relação à IE.

Tabela 1

Resultados da regressão do Modelo 1: influência do comportamento planejado na IE

\begin{tabular}{lllllll}
\hline & $\mathrm{R}$ & $\mathrm{R} 2$ & R2 ajustado & Erro & F & ANOVA - Sig. \\
\hline Modelo 1 &, $718 \mathrm{a}$ &, 515 &, 511 &, 69898280 & 130,10 &, 000
\end{tabular}

Nota. Preditores: C1 - Atitude, C2 - Normas Subjetivas, C3 - Percepção e Controle do Comportamento. Variável dependente: C4 - Intenção Empreendedora.

Ao comparar os resultados com os achados no Brasil, nas pesquisas de Souza et al. (2017) e Souza et al. (2018), que utilizaram a versão revista da QIE, elaborada por Liñán et al. (2011), os resultados demonstraram relações positivas e significativas, explicando 57,3\% da variância da IE. A relação entre atitude e intenção demonstrou a maior força dentre as relações observadas.

Também, ao se compararem os resultados com pesquisas realizadas em outros países, como Portugal, na pesquisa de Oliveira, Vieira, Laguía, Moriano e Soares (2016), o modelo permitiu explicar $40 \%$ da variância da IE, semelhante ao que foi encontrado por Moriano et al. (2012), na Espanha, com 39\% da variância.

Dando continuidade às análises do Modelo 1, a Tabela 2 demonstra os resultados do coeficiente de regressão padronizados e indica que a AP possui maior força preditiva em relação a IE do que os demais constructos da regressão $(\beta=0,447)$, seguido da PCC $(\beta=$ 0,441). O constructo NS não alcançou um nível de significância aceitável, corroborando as pesquisas citadas. 
Tabela 2

Resultado da regressão: coeficientes do Modelo 1

\begin{tabular}{|c|c|c|c|c|c|}
\hline Modelo 1 & $\beta$ & $\begin{array}{l}\text { Erro } \\
\text { padrão }\end{array}$ & $\mathrm{T}$ & $\begin{array}{l}\text { P- } \\
\text { value }\end{array}$ & Sig. \\
\hline $\mathrm{C} 1$ - Atitude x C4 - Intenção Empreendedora & ,447 & ,036 & 11,663 & ,000 & * \\
\hline C2 - Normas Subjetivas x C4 - Intenção Empreendedora & ,068 & ,038 & 1,83 & ,068 & SS \\
\hline $\begin{array}{l}\text { C3 - Percepção e Controle do Comportamento x C4 - Intenção } \\
\text { Empreendedora }\end{array}$ & ,421 & ,037 & 10,919 &, 000 & $*$ \\
\hline
\end{tabular}

Nota. $\mathrm{SS}$ - Sem significância, ${ }^{*} \mathrm{p}<0,05$. Preditores: $\mathrm{C} 1$ - Atitude, C2 - Normas Subjetivas, C3 - Percepção e Controle. Variável dependente: C4 - Intenção Empreendedora.

Ao se verificar se todas as variáveis explicativas apresentam significância $\mathrm{p}<0,05$, o Constructo 2 - NS - não alcançou a significância aceitável. A partir desse resultado, esse constructo deve ser excluído do modelo e, com a exclusão, deve-se analisar novamente o modelo de regressão, sem considerá-lo.

Deve ser ressaltado que esse constructo também não foi significativo na pesquisa de Almeida (2013) com relação aos universitários, com exceção de Cabo Verde e da região Norte do Brasil, que apresentaram coeficientes negativos e estatisticamente significativos. Nos achados de Nguyen (2017), Souza et al. (2017) e Souza et al (2018), também se verificou que as NS não conseguem gerar um impacto significativo na intenção empresarial. Desde o estudo anterior de Liñán e Chen (2009) se encontra indicação de que o componente de NS, ou apoio social em relação ao empreendedorismo, tem dificuldade de predizer as intenções empreendedoras e, por isso, tem sido removido de alguns instrumentos que mensuram IE. As NS são o componente mais social do modelo, uma vez que incorporam a influência de pessoas significativas para o sujeito na decisão de desenvolver a sua carreira profissional por meio do empreendedorismo (Ajzen, 1987).

A partir do resultado de não significância do constructo Normas Subjetivas, procedeuse a uma nova regressão, somente considerando os constructos C1 - Atitude e C3 - Percepção e Controle do Comportamento. Conforme Tabela 3, apresenta-se o resultado na nova regressão.

Tabela 3

Resultados da regressão do Modelo 2

\begin{tabular}{llllll}
\hline $\mathrm{R}$ & $\mathrm{R} 2$ & $\mathrm{R} 2$ ajustado & Erro & $\mathrm{F}$ & ANOVA - Sig.
\end{tabular}




\begin{tabular}{lllllll}
\hline Modelo 2 &, $715 \mathrm{a}$ &, 511 &, 508 &, 70122068 & 192,238 &, 000
\end{tabular}

Nota. Preditores: C1 - Atitude, C3 - Percepção e Controle do Comportamento. Variável dependente: C4 Intenção Empreendedora.

Ao se analisar o resultado da nova regressão, é possível visualizar que as mudanças foram mínimas, com o percentual de explicação variando de 51,5 a 51,1\%, quando foi retirado o Constructo 2 - Normas Subjetivas. Pode-se perceber, também, conforme Tabela 4, uma pequena alteração nos valores de $\beta$ para os dois constructos presentes no segundo modelo, C1 - Atitudes Pessoais - e C3 - Percepção e Controle do Comportamento. Esse resultado demonstra que, ao se retirarem as NS do modelo, ocorre uma alteração positiva no nível de influência $(\beta)$ dos demais constructos em relação à IE.

Tabela 4

Resultado da regressão: coeficientes do Modelo 2

\begin{tabular}{|c|c|c|c|c|c|}
\hline Modelo 2 & $\beta$ & $\begin{array}{l}\text { Erro } \\
\text { padrão }\end{array}$ & $\mathrm{T}$ & $\begin{array}{l}\mathrm{P}- \\
\text { value }\end{array}$ & Sig. \\
\hline C1 - Atitude x C4 - Intenção Empreendedora & ,454 & 038 & 11,869 & 000 & $*$ \\
\hline $\begin{array}{l}\text { C3 - Percepção e Controle do Comportamento x C4 - Intenção } \\
\text { Empreendedora }\end{array}$ & ,430 &, 038 & 11,241 &, 000 & $*$ \\
\hline
\end{tabular}

Nota. ${ }^{*} \mathrm{p}<0,05$. Preditores: $\mathrm{C} 1$ - Atitude, C3 - Percepção e Controle do Comportamento. Variável dependente: C4 - Intenção Empreendedora.

Considerando as ligações propostas, o novo modelo sugere que a relação entre atitude e intenção demonstra a maior força dentre as relações observadas. Contribue para as relações teóricas observadas entre atitudes e IE, em que o nível de impacto gerado pela AP é maior que o gerado pelo PCC em relação à IE. A atitude é determinada por diversas crenças da pessoa em relação ao objeto (coisa, pessoa ou instituição) e por sua avaliação dessas crenças. Essa avaliação é o componente mais afetivo da atitude, determinando a motivação e a força da intenção do comportamento (Ajzen, 1987). Os valores que a pessoa carrega consigo servem para estabelecer normas compartilhadas que definem o tipo de comportamento apropriado nas diversas situações, além de servir para justificar o motivo daquela escolha (Schwartz, 1994). Buscando entender a influência dos valores na IE dos estudantes pesquisados, a próxima subseção apresenta os resultados dessa análise. 


\subsection{Influência dos Valores Humanos na Intenção Empreendedora}

A terceira regressão teve como objetivo explicar a influência dos valores humanos na IE, incluindo como variáveis independentes: C5 - Abertura à Mudança, C6 Autotranscendência, C7 - Conservação, C8 - Autopromoção, às dimensões já analisadas anteriormente, que compõem a TCP: C1 - Atitude Pessoal, C2 - Normas Subjetivas, C3 Percepção e Controle do Comportamento. Os resultados podem ser observados na Tabela 5.

Tabela 5

Resultado da regressão do Modelo 3

\begin{tabular}{lllllll}
\hline & $\mathrm{R}$ & $\mathrm{R} 2$ & $\mathrm{R} 2$ ajustado & Erro padrão & $\mathrm{F}$ & ANOVA - Sig. \\
\hline Modelo 3 &, $726 \mathrm{a}$ &, 528 &, 518 &, 69394920 & 57,904 &, 000
\end{tabular}

Nota. Preditores: C1 - Atitude Pessoal, C2 - Normas Subjetivas, C3 - Percepção e Controle do Comportamento, C5 - Abertura à Mudança, C6 - Autotranscendência, C7 - Conservação, C8 - Autopromoção. Variável dependente: C4 - Intenção Empreendedora

Conforme se observa na Tabela 6, os preditores mais importantes foram os valores de C1 - Atitude Pessoal, C3 - Percepção e Controle do Comportamento e C8 - Autopromoção. Da mesma forma, apenas esses três constructos se mostraram significativos no Modelo 3, com $\mathrm{p}<0,05$. Ou seja, ao incluir a dimensão valores humanos, das quatro dimensões analisadas, apenas a C8 - Autopromoção se mostrou significativa, com $\mathrm{p}<0,05$.

Tabela 6

Resultado da regressão: coeficientes do Modelo 3

\begin{tabular}{|c|c|c|c|c|c|}
\hline Modelo 3 & $\beta$ & $\begin{array}{l}\text { Erro } \\
\text { padrão }\end{array}$ & $\mathrm{T}$ & $\begin{array}{l}\text { P- } \\
\text { value }\end{array}$ & Sig. \\
\hline C1 - Atitude x C4 - Intenção Empreendedora & 450 & ,038 & 11,787 & ,000 & $*$ \\
\hline C2 - Normas Subjetivas x C4 - Intenção Empreendedora & ,072 &, 037 & 1,935 &, 054 & SS \\
\hline $\begin{array}{l}\text { C3 - Percepção e Controle do Comportamento x C4 - Intenção } \\
\text { Empreendedora }\end{array}$ & ,423 & ,039 & 10,957 &, 000 & * \\
\hline C5 - Abertura à Mudança x C4 - Intenção Empreendedora &,- 068 & ,058 & $-1,186$ & ,236 & SS \\
\hline C6 - Autotranscedência x C4 - Intenção Empreendedora &, 060 & ,064 & ,926 &, 355 & SS \\
\hline C7 - Conservação x C4 - Intenção Empreendedora &,- 079 &, 054 & $-1,469$ & , 143 & SS \\
\hline C8 - Autopromoção x C4 - Intenção Empreendedora & ,127 &, 045 & 2,848 & ,005 & $*$ \\
\hline
\end{tabular}


Nota. SS - Sem significância, * p < 0,05. Preditores: C1 - Atitude, C2 - Normas Subjetivas, C3 - Percepção e Controle do Comportamento, C5 - Abertura à Mudança, C6 - Autotranscedência, C7 - Conservação, C8 Autopromoção. Variável dependente: C4 - Intenção Empreendedora.

A autopromoção está relacionada à busca pelo próprio sucesso relativo e domínio sobre os outros (realização e poder) (Schwartz, 2005), que se opõe ao Constructo 6 Autotranscedência. Essa ideia de oposição e compatibilidade de valores se encontra presente na proposta teórica de Schwartz (2005) das relações entre os tipos de valores, e a distância entre os tipos motivacionais denota antagonismo entre suas motivações subjacentes. Assim, nem todos os valores necessariamente estão presentes em determinados comportamentos dos indivíduos.

Nessa ótica, assim como afirmado por Porto e Tamayo (2005), o sistema de valores de um indivíduo representa uma hierarquia de prioridades, constituído pelo grau de importância que cada valor tem para aquela pessoa, diferenciando o que é prioritário do que é secundário. Nesse sentido, com relação à IE dos alunos pesquisados, a única dimensão de valor humano que se mostrou significativa, encontrado nesta pesquisa, foi a de autopromoção. Voltando às dimensões do comportamento planejado, novamente o Constructo 2 - Normas Subjetivas não se mostrou significativo. A partir da análise da significância dos constructos, procedeu-se a retirada dos itens que não apresentaram significância e, a partir disso, realizou-se uma nova regressão, demonstrada na Tabela 7.

Tabela 7

Resultado da regressão: Modelo 4

\begin{tabular}{lllllll}
\hline & $\mathrm{R}$ & $\mathrm{R} 2$ & $\mathrm{R} 2$ ajustado & Erro padrão & $\mathrm{F}$ & ANOVA - Sig. \\
\hline Modelo 4 &, $720 \mathrm{a}$ &, 518 &, 514 &, 69709714 & 131,468 &, $000 \mathrm{a}$
\end{tabular}

Nota. Preditores: C1 - Atitude, C3 - Percepção e Controle do Comportamento, C8 - Autopromoção. Variável dependente: C4 - Intenção Empreendedora.

A regressão foi significativa, pois o R2 foi significantemente diferente de zero $(\mathrm{F}=131,468 ; \mathrm{p}<0,001)$, indicando que a dimensão de valores humanos de autopromoção, adicionada aos demais elementos da TCP, pode predizer a Intenção Empreendedora dos alunos pesquisados. O Modelo 4 explica 51,8\% da variância na IE. Se comparado ao Modelo 2 - que apresenta a regressão somente com as dimensões da TCP e explicou $51,1 \%$ da variância na IE dos alunos pesquisados -, não apresentou diferenças significativas na predição das intenções. Ainda assim, permite entender melhor o principal antecedente da IE, as atitudes 
com relação ao empreendedorismo, que se mantém como o melhor preditor da IE nos dois modelos, com os valores de $\beta$ de 0,451 no Modelo 2 e de 0,453 no Modelo 4, conforme observado na Tabela 8.

Tabela 8

Resultado da regressão: coeficientes do Modelo 4

\begin{tabular}{llllll}
\hline Modelo 4 & $\beta$ & Erro padrão & T & P-value & Sig. \\
\hline C1 - Atitude x C4 - Intenção Empreendedora &, 453 &, 038 & 11,906 &, 000 & $*$ \\
C3 - Percepção e Controle do Comportamento x C4 - &, 429 &, 038 & 10,267 &, 000 & $*$ \\
Intenção Empreendedora & & & & & \\
C8 - Autopromoção x C4 - Intenção Empreendedora &, 089 &, 036 & 2,317 &, 021 & $*$
\end{tabular}

Nota. * p < 0,05. Preditores: C1 - Atitude, C3 - Percepção e Controle do Comportamento, C8 - Autopromoção. Variável dependente: C4 - Intenção Empreendedora.

Outra informação importante é fornecida pelo coeficiente $\beta$, que demonstra uma influência positiva nesses três constructos, sendo o C1 - Atitude o maior influenciador, com $\beta=0,453$, seguido do C3 - Percepção e Controle do Comportamento, com $\beta=0,429$, e do C8 - Autopromoção, com $\beta=0,089$. Considerando a diversidade da amostra e da complexibilidade de identificar os valores humanos dos indivíduos, o resultado apresenta-se positivo. Segundo o levantamento de Schwartz (2001), a partir da literatura de valores, um valor transcende situações específicas e guia a seleção ou avaliação de comportamentos, pessoas e acontecimentos, ordenado em função de sua importância relativa a outros valores para formar um sistema de prioridades. Nessa ótica, a autopromoção se mostrou significativa nesse contexto de análise da IE dos alunos, transcendendo a busca por poder, prestígio, sucesso, riqueza, autoridade e poder social. Esse eixo é ordenado com base na motivação da pessoa para promover os seus próprios interesses e bem-estar, e se opõe ao eixo de autotranscedência, que promove os interesses coletivos e o bem-estar dos outros (Porto \& Tamayo, 2005). Cabe destacar que, embora o fator autopromoção tenha se mostrado significativo, com $\beta=0,089$, esse fator pode ser considerado baixo, indicando que a influência é também baixa sobre o constructo dependente.

A presente pesquisa também corrobora os achados de Olmos e Castilho (2015), que identificaram características que afetam positivamente a intenção empresarial. Desse modo, comparando-se os traços de personalidade com os valores e os resultados, fica demonstrado 
que os traços de personalidade afetam a intenção empresarial, exercendo efeitos positivos altamente significativos $(\mathrm{p}<0,01)$.

Nesse sentido, os valores implicam uma preferência, distinguindo o que é importante para o indivíduo. Contudo, vale ressaltar que os valores humanos não se limitam a uma perspectiva individual. Ao retomar a literatura, visualiza-se que os valores de determinada cultura são mediados pelo contexto em que o indivíduo empreendedor está inserido.

\section{Considerações Finais}

A revisão da literatura na qual se baseia o presente estudo evidencia o fenômeno do empreendedorismo como uma dinâmica complexa, multifacetada, que interliga os ecossistemas e evoca a questão entre políticos, educadores e praticantes (Vanevenhoven, 2013). O empreendedorismo apresenta ainda aspectos econômicos, psicossociais, gerenciais, históricos, entre outros, todos inter-relacionados e complementares, o que contribui para a afirmação de que o processo empreendedor não pode ser visto de maneira unidimensional (Franco \& Gouvêa, 2017).

Quanto à questão de pesquisa enunciada, e que norteou o estudo, essa foi respondida, por meio da consecução do objetivo de pesquisa: mensurar a Atitude Pessoal, as Normas Subjetivas, o Controle do Comportamento Percebido e os Valores Humanos na Intenção Empreendedora de estudantes universitários da região Sudoeste do Paraná, Brasil.

Por meio de uma abordagem descritiva, com método quantitativo, e adoção de procedimentos estatísticos, realizou-se a pesquisa de campo. Essa considerou uma amostra significativa de 403 estudantes universitários, dos últimos períodos de cursos de Administração de Empresas, na modalidade presencial, oferecidos por 11 IES estabelecidas na região Sudoeste do Parará, Brasil. Validaram-se 371 respostas, tendo sido considerada adequada para o estudo.

A análise dos dados seguiu a Regressão Linear Múltipla, verificando a influência de cada constructo na Intenção Empreendedora. Os instrumentos de coleta utilizados, QIE e QPV, com base na TCP, de Ajzen (1991) e na TVH, de Schwartz (2001), respectivamente. Esses dois instrumentos foram complementados por três itens do instrumento de Thompson (2009). As características dos respondentes e das instituições estudadas foram consideradas para identificação sociodemográficas. A análise de dados permitiu mensurar a influência do comportamento planejado e dos valores humanos na intenção empreendedora (IE) dos estudantes universitários de 11 IES da região Sudoeste do Parará, Brasil. 
Os resultados obtidos com a análise de dados, quanto aos constructos da TCP, de Ajzen (2001), evidenciam a influência positiva de AP e de PCC, e reafirmam a TCP. Esses dois constructos se revelam como preditores das intenções de empreender, e confirmam a IE dos amostrados. NS não se mostra com os níveis de significância necessários.

Para os constructos da THV, de valores humanos, a autopromoção se mostra significativa. Demonstra positividade na IE dos alunos. O constructo autopromoção encerra, em si mesmo, valores de realização e poder. Significam busca por "status" social e prestígio, controle ou domínio sobre pessoas e recursos, busca pelo sucesso pessoal, por meio da demonstração de competência, de acordo com padrões sociais, e de valores característicos de culturas individualistas. A indicação da autopromoção como um fator de valor humano abre possibilidades para que outros fatores possam emergir em novas pesquisas. A autopromoção, assim, se revela como novo aspecto em pesquisas de IE. Traz abordagem que pouco se reflete nos estudos de IE e na literatura do tema.

O modelo baseado na TCP permite explicar $51,1 \%$ da variância da IE, enquanto o THV explica $51,8 \%$ da variância na IE, constituindo-se em valores médios. Esse resultado evidencia que é pouco alterada a variância entre os dois modelos. E, significa que a IE parece sofrer influências culturais, onde o local e o contexto interferem nos seus valores e, consequentemente, na IE.

Esses resultados, mesmo iniciais, se mostram significativos quanto à adoção simultânea dos dois modelos teóricos, da TCP (Ajzen, 1991) e da THV (Schwartz, 2001), quanto à mensuração da variância da IE. Permitem vislumbrar que a adoção conjunta dos dois modelos complementa e amplia a perspectiva teórica de mensuração da IE. E permite evidenciar um interesse mediano dos alunos pela carreira empreendedora, por meio de AP, PCC e VH. Indicam, algo novo, inédito e original para a teoria de IE.

Considera-se que esses resultados, sendo iniciais, merecem aprofundamento, novos estudos e análises para melhor entendimento e confirmação. Assim, outras análises se apresentam como desejáveis para estimular a aproximação entre essas duas teorias: A TCP (Ajzen, 1991) e a THV (Schwartz, 2001). A literatura de IE pouco revela sobre esses dois enfoques, abordados simultaneamente.

Esses resultados, da mesma forma, abrem perspectivas na prática da gestão universitária das IES pesquisadas. $\mathrm{O}$ interesse manifestado pelos alunos quanto à realização pessoal, por meio da carreira empreendedora, é um resultado que não pode ser ignorado. Ampara e conduz à reflexão da necessidade dessas IES se voltarem para a adoção da educação empreendedora. E, a educação empreendedora do ponto de vista não só do ensino 
de graduação, mas em outros níveis e aspectos de pesquisa e de extensão universitária. No âmbito das IES, esses aspectos alertam para a formação de melhores empreendedores, quanto às competências e habilidades voltadas para o empreender, e o estímulo às ações voltadas para aperfeiçoamento e desenvolvimento do empreendedorismo. O estudo de Vasconcelos et al. (2020) deixa claro que a intenção empreendedora, o comportamento empreendedor inicial e a Teoria Sociocognitiva do Desenvolvimento de Carreira se completam e se revelam como favoráveis no ambiente acadêmico.

De forma mais específica, cabe chamar atenção e destacar um fato interessante que se revelou no decorrer da pesquisa, e que reforça esse ponto de vista: das 11 IES pesquisadas, apenas cinco ofereciam algum tipo de programa de ensino do empreendedorismo extraclasse, e apenas 47,2\% dos alunos pesquisados haviam participado de programas de empreendedorismo extracurriculares ofertados pelas instituições. Mesmo assim, nesse ambiente, os alunos revelaram intenção de empreender e interesse quanto à carreira empreendedora. Assim, os alunos estão propensos a empreender. E, há lugar para o aprendizado do "se tornar empreendedor".

Sabendo-se que no contexto acadêmico as atividades de educação empreendedora são apontadas como importantes para estimular o desenvolvimento do empreendedorismo, possibilitando o enfrentamento de sérios desafios econômicos e sociais (Ozaralli \& Rivenburgh, 2016), essas ações são importantes para o fortalecimento das economias locais e regionais.

Considerando que no Brasil as pesquisas ainda são escassas sobre o tema da IE, esse se coloca como foco de interesse. Necessário se faz continuar realizando estudos nessa direção. E, desenvolver estudos à semelhança desse, considerando conjuntamente as duas teorias: TCP (Ajzen, 1991) e THV (Schwartz, 2001). A adoção teórica de dois modelos que se complementam, com a ampliação da mensuração dos constructos para IE, ainda que com resultados médios, se mostra como um fato novo, relevante, e deve ser evidenciado. Sendo inicial esse estudo, ou seja, uma das primeiras pesquisas nesse sentido, este se mostra como uma perspectiva inovadora, que pode ser retomada. Esse aspecto teórico, da combinação das duas teorias é inédito e se reveste de originalidade e valor para a pesquisa científica de IE.

A evidência de que a autopromoção pode ser um indicador do interesse dos alunos de graduação pela carreira empreendedora também surgiu como um aspecto diferenciado no estudo, indicando a possibilidade de que outros valores humanos se apresentem em futuras pesquisas. 
De forma geral, o estudo aqui oportuniza ainda discussões mais abrangentes sobre IE e educação empreendedora, no contexto das IES brasileiras, no sentido de contribuir para essas duas áreas de enfoque.

Considerar métodos e técnicas de pesquisa e contextos diferenciados para a pesquisas de campo também se apresentam como desejáveis para continuidade de estudos em IE.

\section{Referências}

Ajzen, I. (1987). Attitudes, traits, and actions: dispositional prediction of behavior in social psychology. In L. Berkowitz (Ed.), Advances in Experimental Social Psychology (v. 20, pp. 1-6). San Diego: Academic Press.

Ajzen, I. (1991). The theory of planned behavior. Organizational and Human Decision Processes, 50(12), 179-211.

Ajzen, I. (2001). Nature and operation of attitudes. Annual Review of Psychology, 52, 27-58.

Ajzen, I. (2002). Perceived behavioral control, self-efficacy, locus of control, and the theory of planned behavior. Journal of Applied Social Psychology, 32(1), 1-20.

Ajzen, I. (2005). Attitudes, personality and behavior (2nd ed.). England: Open University Press, McGraw-Hill.

Ajzen, I. (2011). Behavioral interventions: Design and evaluation guided by the theory of planned behavior. In M. M. Mark, S. I. Donaldson, \& B. Campbel (Eds.), Social Psychology and Evaluation (pp. 72-100). New York: Guilford Press.

Ajzen, I., \& Fishbein, M. (2000). Attitudes and the attitude-behavior relation: Reasoned and automatic processes. In E. W. Stroebe, \& M. Hewstone (Orgs.), European Review of Social Psychology (v. 11, pp. 1-33). New York: John Wiley \& Sons.

Almeida, G. O. (2013). Valores, atitudes e intenção empreendedora: Um estudo com universitários brasileiros e cabo-verdianos (Tese de Doutorado, Escola Brasileira de Administração Pública e de Empresas, Rio de Janeiro, Brasil).

Araújo, E. G., \& Bayon, M. C. (2017). Fatores socioculturais e o empreendedorismo dos jovens nas regiões rurais. Revista Brasileira de Gestão de Negócios, 19(64), 200-218.

Arce, J. L. H. (2019). Propuesta y comprobación de una extensión del modelo de valores personales de Schwartz (1992) y evaluación de la utilidad predictiva en el consumo. (Tese de Doutorado, Universidad de Murcia, Múrcia, Espanha).

Bittencourt, A. C. (2019). A influência das práticas empreendedoras de uma universidade na formação de ecossistemas de inovação: Um estudo à luz da teoria do trabalho 
institucional. (Tese de Doutorado, Universidade do Vale dos Sinos, São Leopoldo, Brasil).

Corrêa, J. C. S., Silveira, R. L. L., \& Brochier, R. B. (2019). Sobre o conceito de desenvolvimento regional: Notas para debate [Edição especial]. Revista Brasileira de Gestão e Desenvolvimento Regional G\&DR, 15(7), 3-15.

Couto, C. L. P., Mariano, S. R. H., \& Mayer, V. F. (2010). Medição da intenção empreendedora no contexto brasileiro: Desafios da aplicação de um modelo internacional. Anais do Encontro da ANPAD, Rio de Janeiro, 34.

Elfving, J., Brännback, M., \& Carsrud, A. (2009). Toward a contextual model of entrepreneurial intentions. In A. Carsrud, \& M. Brännback (Eds.), Understanding the entrepreneurial mind: Opening the black box (pp. 23-33). New York: Springer.

Fayolle, A., \& Liñán, F. (2014). The future of research on entrepreneurial intentions. Journal of Business Research, 67, 663-666.

Fernandes, N. P., D’Avila, L. C., Cruz, A. P. C., \& Pereira, E. F. Z., Jr. (2020). Quem é o empreendedor? A busca por uma definição do conceito através da produção científica brasileira. Revista Brasileira de Gestão e Inovação, 7(3), 27-62.

Ferreira, A., Loiola, E., \& Gondim, S. M. (2017). Preditores individuais e contextuais da intenção empreendedora entre universitários: Revisão de literatura. Cadernos Ebape.BR, 15(2), 292-308.

Fragoso, R., Rocha-Junior, W., \& Xavier, A. (2019). Determinant factors of entrepreneurial intention among university students in Brazil and Portugal. Journal of Small Business \& Entrepreneurship, 2169-2610. http://dx.doi.org/10.1080/08276331.2018.1551459

Franco, J. O. B., \& Gouvêa, J. B. (2017). A cronologia dos estudos sobre o empreendedorismo. Revista de Empreendedorismo e Gestão de Pequenas Empresas, 6(2), 553-574.

Galvão, A. R. (2019). A importância da formação em empreendedorismo no desenvolvimento regional: O programa de empreendedorismo na região do sabor. (Tese de Doutorado, Universidade da Beira Interior, Covilhã, Portugal).

Garcez, A. P. B. (2019). Efeitos dos fatores cognitivos e psicológicos em ambiente de praxe académica na intenção empreendedora: Um estudo aplicado à FCSH da UBI (versão final após defesa). (Dissertação de Mestrado, Universidade da Beira Interior, Covilhã, Portugal). 
Jie, S., \& Harms, R. (2017). Cross-cultural competences and international entrepreneurial intention: A study on entrepreneurship education. Education Research International, $17(1), 1-12$.

Joseph, I. (2017). Factors influencing international student entrepreneurial intention in Malaysia. American Journal of Industrial and Business Management, 7, 424-428.

Kasuma, J., Sapenee, M. K., Naimullah, B. S. S., Rahman, D. H. A. A., \& Adenan, M. A. B. (2019). Personal capabilities and social factor towards entrepreneurial intention: Empirical evidence of science and technology undergraduate students. Journal of International Business, Economics and Entrepreneurship, 4(1).

Krueger, N. F., Reilly, M. D., \& Carsrud, A. L. (2000). Competing models of entrepreneurial intentions. Journal of Business Venturing, 15, 411-432.

Liñán, F., \& Chen, Y. W. (2009). Development and cross-cultural application of a specific instrument to measure entrepreneurial intentions. Entrepreneurship Theory and Practice, 33 (3), 593-617.

Liñán, F., \& Fayolle, A. (2015). A systematic literature review on entrepreneurial intentions: Citation, thematic analyses, and research agenda. International Entrepreneurship and Management Journal, 11(4), 907-933.

Liñán, F., Nabi, G., \& Krueger, N. (2013). British and Spanish entrepreneurial intentions: A comparative study. Revista de Economia Mundial, 33, 73-103.

Liñán, F., Urbano, D., \& Guerrero, M. (2011). Regional variations in entrepreneurial cognitions: Start-up intentions of university students in Spain. Entrepreneurship \& Regional Development, 23(3/4), 187-215.

Marcon, D. L., Silveira, A., \& Frizon, J. A. (2020). Empreender ou não? Fatores condicionantes da intenção empreendedora. Revista de Administração FACES Journal, 20(1). http://dx.doi.org/10.21714/1984-6975FACES2020V19N1ART7526

Martins, T. O., Sales, D. R., \& Reis, M. T., Neto. (2020). A influência dos valores e crenças no comportamento humano. Brazilian Journal of Development, 6(1), 2698-2711.

Martins, F. S., Santos, E. B. A., \& Silveira, A. (2019). Entrepreneurial intention: Categorization, classification of constructs and proposition of a model. Brazilian Business Review, 16, 46-62. 
Melo, F. L. N. B., Silva, R. R., \& Almeida, T. N. V. (2019). Gênero e empreendedorismo: Um estudo comparativo entre as abordagens 'Causation e Effectuation'. Brazilian Business Review, 16(3). http://dx.doi.org/10.15728/bbr.2019.16.3.5

Monteiro, M. M. L., Silva, G. B., Sousa, F. R. L., \& Melo, C. X. (2020). Intenção empreendedora e formação acadêmica: Um estudo com acadêmicos de administração em uma instituição pública. Research, Society and Development, 9(1), e115911736.

Moriano, J. A., Gorgievski, M. J., Laguna, M., \& Stephan, U. (2012). A cross-cultural approach to understanding entrepreneurial intention. Journal of Career Development, $39(2), 162-185$.

Moriano, J. A., Palací, F. J., \& Morales, J. F. (2006). Adaptación y validación en España de la escala de autoeficácia emprendedora. Revista de Psicología Social, 21(1), 51-64.

Nguyen, C. (2017). Entrepreneurial intention of international business students in Viet Nam: A survey of the country joining the trans-pacific partnership. Journal of Innovation and Entrepreneurship, 6(7), 1-13.

Oliveira, B. M. F., Vieira, D. A., Laguía, A., Moriano, J. A., \& Soares, V. J. S. (2016). Intenção empreendedora em estudantes universitários: Adaptação e validação de uma escala (QIE). Avaliação Psicológica, 15(2), 187-196.

Olmos, R. E., \& Castilho, A. S. (2015). Personality traits versus work values: Comparing psychological theories on entrepreneurial intention. Journal of Businees Research, 68(7), 1595-1598.

Ozaralli, N., \& Rivenburgh, N. K. (2016). Intenção empreendedora: Antecedentes do comportamento empresarial nos EUA e na Turquia. Journal of Global Entrepreneurship Research, 6(3).

Paiva, L. E. B., Sousa, E. S., Lima, R. C. B., \& Silva, D. (2020). Comportamento planejado e crenças religiosas como antecedentes da intenção empreendedora: Um estudo com universitários. Revista de Administração Mackenzie, 21(2).

Pecly, P. H. D., \& Ribeiro, P. C. C. (2015). A influência da cultura empreendedora no empreendedorismo dos países do BRICS: Uma revisão bibliográfica. Anais do Congresso nacional de excelência em gestão, 11. Recuperado de http://www.inovarse.org/sites/default/files/T_15_443.pdf

Porto, J. B., \& Tamayo, A. (2005). Valores e comportamentos nas organizações. Petrópolis: Vozes. 
Renzi, A., Henz, A. P., \& Rippel, R. (2019). Desenvolvimento econômico: Do crescimento à prosperidade. Revista Brasileira de Gestão e Desenvolvimento Regional G\&DR, 15(6), $65-77$.

Rueda, S., Moriano, J. A., \& Liñán, F. (2015). Validating a theory of planned behavior questionnaire to measure entrepreneurial intention. In A. Fayolle, P. Kyrö, \& F. Liñán (Eds.), Developing, shaping and growing entrepreneurship (pp. 68-78). Cheltenham: Edward Elgar.

Saffu, K. (2003). The role and impact of culture on south pacific island entrepreneurs. International Journal of Entrepreneurial Behaviour \& Research, 9(2), 55-73.

Santos, C. C., Teston, S. F., Zawadski, P., Lizote, S. A., \& Machado, H. P. V. (2020). Capacidade absortiva individual e intenção empreendedora em sucessores de propriedades rurais. Revista de Administração Mackenzie, 21(3). http://dx.doi.org/10.1590/1678-6971/eramr200045

Santos, E. I., Sá Barreto, R. C., \& Guzman, S. J. M. (2017). Modelo estrutural para os fatores determinantes da oferta de empreendedores criativos: Ilhéus e Itabuna. Revista de Empreendedorismo e Gestão de Pequenas Empresas, 6(1), 160-195.

Schaefer, R., Nishi, J. M., Grohmann, M. Z., Löbler, M. L., \& Minello, I. F. (2017). Valores pessoais, atitudes e intenção empreendedora: Um estudo com estudantes de graduação em administração. Revista Economia \& Gestão, 17(47), 123-143.

Shumpeter, J. A. (1982). Teoria do desenvolvimento econômico: Uma investigação sobre lucros, capital, crédito, juro e o ciclo econômico. São Paulo: Abril Cultural.

Schwartz, S. H. (1994). Are there universal aspects in the structure and contents of human values? Journal of Social Issues, 50, 19-45.

Schwartz, S. H. (2001). ¿Existen aspectos universales en la estructura y contenido de los valores humanos? In M. Ros, \& V. V. Gouveia (Coord.), Psicología social de los valores humanos (pp. 53-77). Madrid: Biblioteca Nueva.

Schwartz, S. H. (2005). Validade e aplicabilidade da teoria de valores. In J. B. Porto, \& A. Tamayo (Orgs.), Valores e comportamentos nas organizações (pp. 56-92). Rio de Janeiro: Vozes.

Schwartz, S. H. (2006). Basic human values. An overview. Technical report. The Hebrew University of Jerusalem. Recuperado de http://www.yourmorals.org/schwartz.2006.basic\%20human\%20values.pdf 
Schwartz, S. H. (2012). An overview of the Schwartz theory of basic values. Online Readings in Psychology and Culture, 2, 2012.

Schwartz, S. H., Cieciuch, J., Vecchione, M., Torres, C., Dirilemgumus, O., \& Butenko, T. (2017). Value tradeoffs and behavior in five countries: Validating 19 refined values. European Journal of Social Psychology, 47(3), 241-258.

Silva, A. W. P., Oliveira, B. N. F., Castro, A. B. C., Silva, P. M. M., \& Veiga, A. R., Neto. (2020). Comportamento empreendedor: Um mapeamento da produção científica nacional (2000-2020) e proposição de uma agenda de pesquisa. Revista de Administração Unimep, $18(1), 155-191$.

Silveira, A., Bizarrias, F. S., \& Carmo, H. M. O. (2017). Entrepreneurial intention of participants of the startup weekend: Longitudinal analysis. International Journal of Advances in Management and Economics, 6, 90-102.

Silveira, A., Ferreira, C. C., Silvente, G. A., \& Cunha, J. J. C. (2017). Factors and approaches of entrepreneurial intention. Revista de Empreendedorismo e Gestão de Pequenas Empresas, 6(2), 263-290.

Sousa, E. S. (2020). Orientação religiosa, valores pessoais e intenção empreendedora: evidências empíricas no Brasil e em Portugal. (Tese de Doutorado, Universidade Federal do Ceará, Fortaleza, Brasil).

Sousa, E. S., Fontenele, R. E. S., Silva, A. L. L., \& Sousa, J. M., Filho. (2019, setembrodezembro). Mapeamento da produção científica internacional sobre intenção $\begin{array}{llll}\text { empreendedora. } & \text { Revista } & \text { GeSec, } & \text { 10(3), }\end{array}$ http://dx.doi.org/10.7769/gesec.v10i3.901

Sousa, M. M. M. (2020). Valores humanos e jeitinho brasileiro: Uma análise da transmissão de pais para filhos. (Dissertação de Mestrado, Universidade Federal do Ceará, Fortaleza, Brasil).

Souza, R. S., \& Silveira, A. (2018). Intención emprendedora en contexto universitario brasileño. Revista Gestão Universitária da América Latina, 11, 297-318.

Souza, R. S., Silveira, A., \& Nascimento, S. (2018). Ampliando a mensuração da intenção empreendedora. Revista de Administração Faces Journal, 17, 74-93.

Streiner, D. L. (2003). Being inconsistent about consistency: When coefficient alpha does and does not matter. Journal of Personality Assessment, 80, 217-222.

Thompson, E. R. (2009, May). Individual entrepreneurial intent: Construct clarification and development of an internationally reliable metric. Entrepreneurship Theory and Practice, 33(3), 669-694. 
Vanevenhoven, J. (2013, July). Advances and challenges in entrepreneurship education. Journal of Small Business Management, 51 (3), 466-470.

Vasconcelos, V. N. S. A., Pedron, C. D., Silveira, A., \& Andrade, D. C. T. (2020, janeiro). Intenção empreendedora, comportamento empreendedor inicial e Teoria Sociocognitiva do Desenvolvimento de Carreira. Revista de Empreendedorismo e Gestão de Pequenas Empresas, 9(1), 159-188.

Watchravesringkan, K., Hodges, N. N., Yurchisin, J., Hegland, J., Karpova, E., Marcketti, S., \& Yan, R.-n. (2014). Modeling entrepreneurial career intentions among undergraduates: An examination of the moderating role of entrepreneurial knowledge and skills. Family and Consumer Sciences Research Journal, 41(3), 325-342.

Submetido em: 09.07.2020

Aceito em: $\quad 12.11 .2020$ 